is rising from winter to summer than when it is falling from summer to winter, agreeing in this respect with what has been observed in similar regions.

The Monthly liecords give, in addition to the month's results, the averages of that month for each station based on previous years' observations. In the review referred to above we drew attention to the temperature observations at Portland as being evidently too high. In the following February (1877) the mistake was rectified, and since then the observations of temperature at this station agree with those made at the other stations. A comparison shows that down to January I 877 the published temperatures at Portland were about $5 \%$ too high. As regards the averages published since then, however, no allowance has been made down to December 1883 for this large error. The result is that while at the other stations of the colony the mean temperatures of the months since February 1877 rise above and fall below their averages as at other places, Portland all but uninterruptedly appears as very much below its average. Indeed, cxcept the unusually warm months of September I 879 and February 1880, not one of the other forty-six months shows a temperature as high as the average. It is the more necessary to draw attention to this point seeing that the faulty mean temperatures of Portland still continue to appear in works on climatology, either in the text, or they have been used along with the means of other places, similarly faulty, in drawing the isothermals of the globe.

\section{HABITS OF BURROWING CRAYFISHES IN THE UNITED STATES}

$\mathrm{O}^{\mathrm{N}}$

May 13, I883, I chanced to enter a meadow a few miles above Washington, on the Virginia side of the Potomac, at the head of a small stream emptying into the river. It was between two hills, at an elevation of 100 feet above the Potomac, and about a mile from the river. Here I saw many clayey mounds covering burrows scattered over the ground irregularly both upon the banks of the stream and in the adjacent meadow, even as far as ten yards from the bed of the brook. My curiosity was aroused, and I explored several of the holes, finding in each a good-sized crayfish, which Prof. Walter Faxon identified as Cambarus arogenes, Girard ( $C$. obesus, Hagen), otherwise known as the burrowing crayfish. I afterwards visited the locality several times, collecting specimens of the mounds and crayfishes, which are now in the United States National Museum, and making observations.

At that time of the year the stream was receding, and the meadow was beginning to diy. At a period not over a monch previous, the meadows, at least as far from the stream as the burrows were found, had been covered with water. Those burrows near the stream were less than six inches deep, and there was a gradual increase in depth as the distance from the stream became greater. Moreover, the holes farthest from the stream were in nearly every case covered by a mound, while those nearer had either a very small chimney or none at all; and subsequent visits proved that at that time of year the mounds were just being constructed, for each time I revisited the place the mounds were more numerous.

The length, width, general direction of the burrows, and number of the openings were extremely variable, and the same is true of the mounds. Fig. I illustrates a typical burrow shown in section. Here the main burrow is very nearly perpendicular, there being but one oblique opening having a very smail mound, and the main mound is somewhat wider than long. Occasionally the burrows are very tortuous, and there are often two or three extra openings, each sometimes covered by a mound. There is every conceivable shape and size in the chimneys, ranging from a mere ridge of mud, evidently the first foundation, to those with a breadth one-half the height. The typical mound is one which covers the perpendicular burrow in Fig. 1, its dimensions being six inches broad. and four high. Two other forms are shown in Fig. 2. The burrows near the stream were seldem more than six inches deep, being nearly perpendicular, with an enlargement at the base, and always with at least one oblique opening. The mounds were usually of yellow clay, although in one place the ground was of fine gravel, and there the chimneys were of the same character. They were always circularly pyramidal in shape, the hole inside being very smooth, but the outside was formed of irregular nodules of clay hardened in the sun and lying just as they fell when dropped from the top of the mound. A small quantity of grass and leaves was mixed through the mound, but this was apparently accidental. The size of the burrows varied from haif an inch to two inches in diameter, being smooth for the entire distance, and nearly uniform in width. Where the burrow was far distant from the stream, the upper part was hard and dry. In the deeper holes I invariably found several enlargements

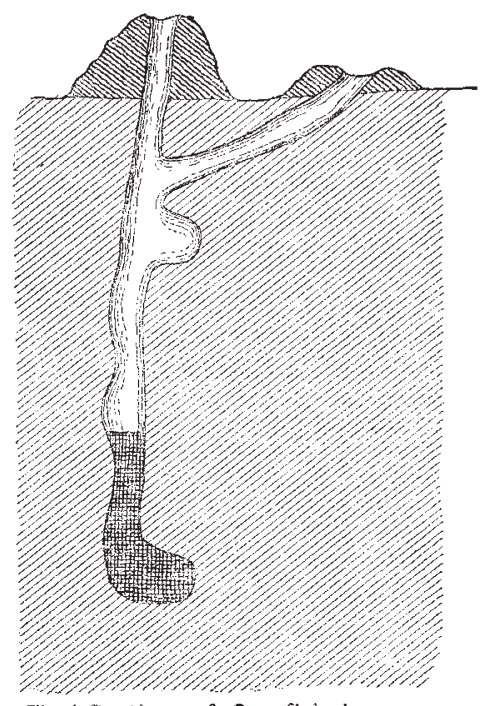

Fig. 1 Section of Crayfish burrow

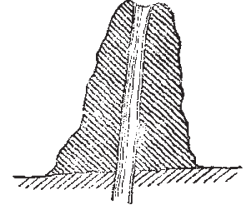

Fig. 2 Crayfish mound

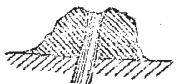

Fig. 2 Crayfish mound at various points in the burrow. Some burrows were three feet deep, indeed they all go down to water, and, as the water in the ground lowers, the burrow is undoubtedly projected deeper. The diagonal openings never at that season of the year have perfect chimneys, and seldom more than a mere rim. In no case did I find any con. nection between two different burrows. In digging after the inhabitants I was seldom able to secure a specimen from the deeper burrows, for I found that the animal always retreated to the extreme end, and when it could go no farther would use its claws in defence. Both males and females have burrows, but they were never found together, each burrow having but a single individual. There is seldom more than a pint of water in each bole, and this is muddy and hardly suitable to sustain life.

The neighbouring brooks and springs were inhabited by another species of crayfish, Cambarus bartonii, but although especial search was made for the burrowing species, in no case was a single specimen found outside of the burrows. C. bartonii was taken both in the swiftly. running portions of the stream, and in the shallow side pools, as well as in the springs at the head of small 
rivers. It would swim about in all directions, and was often found under stones and in little holes and crevices, none of which appeared to have been made for the purpose of retreat, but were accidental. The crayfishes would leave these little retreats whenever disturbed, and swim away down stream out of sight. They were often found some distance from the main stream under rocks that had been covered by the brook at a higher watermark; but although there was very little water under the rocks, and the stream had not covered them for at least two weeks, they showed no tendency to burrow. Nor have I ever found any burrows formed by the river species Cambarus affinis, although I have searched over miles of marsh-land on the Potomac for this purpose.

The brook near where my observations were made was fast decreasing in volume, and would probably continue to do so until in July its bed would be nearly dry. During the wet seasons the meadow is itself covered. Even in the banks of the stream, then under water, there were holes, but they all extended obliquely without exception, there being no perpendicular burrows, and no mounds. The holes extended in about six inches, and there was never a perpendicular branch, nor even an enlargement at the end. I always found the inhabitant near the mouth, and by quickly cutting off the rear part of the hole could force him out, but unless forcibly driven out it would never leave the hole, not even when a stick was thrust in behind it. It was undoubtedly this species that Dr. Godman mentioned in his "Rambles of a Naturalist," and which Dr. Abbott (Am. Nat., I873, p. 8r) refers to C. bartonii. Although I have no proof that this is so, I am inclined to believe that the burrowing crayfishes retire to the stream in winter, and remain there until early spring, when they construct their burrows for the purpose of rearing their young, and escaping the summer droughts. My reason for saying this is that I found one burrow which on my first visit was but six inches deep, and later had been projected to a depth at least twice as great, and the inhabitant was an old female.

I think that after the winter has passed, and while the marsh is still covered with water, impregnation takes place and burrows are immediately begun I do not believe that the same burrow is occupied for more than one year, as it would probably fill up during the winter. At first it burrows diagonally, and as long as the mouth is covered with water is satisfied with this oblique hole. When the water recedes, leaving the opening uncovered, the burrow must be dug deeper, and the economy of a perpendicular burrow must immediately suggest itself. From that time the perpendicular direction is preserved with more or less regularity. Immediately after the perpendicular hole is begun, a shorter opening to the surface is needed for conveying the mud from the nest, and then the perpendicular opening is made. Mud from this and also from the first part of the perpendicular burrow is carried out of the diagonal opening and deposited on the edge. If a freshet occurs before this rim of mud has a chance to harden, it is washed away and no mound is formed over the oblique burrow. After the vertical opening is made, as the hole is bored deeper, mud is deposited on the edge, and the deeper it is dug the higher the mound. I do not think that the chimney is a necessary part of the nest, but simply the result of digging. I carried away several mounds, and in a week revisited the place, and no attempt had been made to replace them; but in one case, where I had, in addition, partly destroyed the burrow by dropping mud into it, there was a simple half rim of mud around the edge, showing that the crayfish had been at work; and as the mud was dry the clearing must have been done soon after my departure. That the crayfish retreats as the water in the ground falls lower and lower, is proved by the fact that at various intervals there are bottle-shaped cavities marking the end of the burrow at an earlier period. A few of those mounds farthest from the stream had their mouths closed by a pellet of mud. It is said that all are closed during the summer months. How these animals can live for months in the muddy, impure water is to me a puzzle. They are very sluggish, possessing none of the quick motions of their allied $C$. bartoniz, for when taken out and placed either in water or on the ground they move very slowly. The power of throwing off their claws when these are grasped is of ten exercised. About the middle of May the eggs hatch, and for a time the young cling to the mother, but I am unable to state how long they remain thus. After hatching they must grow rapidly, and soon the burrow will be too small for them to live in, and they must migrate. It would be interesting to know more about the habits of this peculiar species, about which so little has been written. An interesting point to settle would be how and where it gets its food. The burrow contains none, either animal or vegetable. Food must be procured at night, or when the sun is not shining brightly. In the spring and fall the green stalks of meadow grasses would furnish food, but when these become parched and dry they must either dig after and eat the roots, or search in the stream. I feel satisfied that they do not tunnel among the roots, for if they did so these burrows would be frequently met with. Little has as yet been published upon this subject, and that little covers only two spring months, April and May, and it would be interesting if those who have an opportunity to watch the species during other seasons, or who have observed them at any season of the year, would make known their results.

RALPH S. TARR

\section{THE YOUNG GORILLA OF THE JARDIN DES PLANTES}

THROUGH the courtesy of the editor of La Nature we are able to give an illustration from an instantaneous photograph of a young male gorilla obtained at the commencement of last winter by the Natural History Museum at Paris. It had been imported from the Gaboon, and it was the first living specimen of this great anthropomorphic ape which had been brought to France. Its study would have presented many points of interest, not alone from the Natural History point of view, but also from the opportunity it would have afforded of studying the development of its intellectual faculties. This young specimen was about three years of age, he had already his full complement of milk-teeth, and the long and sharp canines were decidedly longer than the molars. In disposition he appeared to be very different from either the orang-outan or the chimpanzee. While these in a state of captivity are mostly gentle and sociable, this young gorilla on the other hand was savage, morose, and brutal; he never gave his keeper the least mark of affection; he never allowed himself to be touched without evidencing the greatest aversion, and for the most part he returned caresses by snappings. He never took the least part in the games of the other apes, and he most reluctantly tolerated having them near him. He was but little active, and most generally kept himself crourhed up in a corner of the cage, or sitting on a branch with his back up against the wall, and scarcely ever moved but to look about for something to eat. He used his hands with much readiness, and they were extremely well developed. His lips were less mobile than in the chimpanzee, especially the lower lip, which was never pouted out when drinking into a spoon-shaped form. His eyes were extremely mobile, and were crowned with immense superciliary ridges; his nose was flat, with excessively large nostrils, giving him a quite peculiar physiognomy. 